\title{
BUKIT SIGUNTANG: PERANANNYA DALAM AGAMA BUDDHA PADA MASA KERAJAAN SRIWIJAYA
}

Siguntang Hill: Its Role in Buddhism in Sriwijaya Kingdom Period

\author{
Retno Purwanti Nadeak \\ Balai Arkeologi Sumatera Selatan \\ J1. Kancil Putih Lr. Rusa Demang Lebar Daun, Palembang 30136 \\ Email: nretnopurwanti@yahoo.com
}

Naskah diterima: 23-12-2015; direvisi: 15-02-2016; disetujui: 22-03-2016

\begin{abstract}
Siguntang hill is one of the sites from Sriwijaya Kingdom period located in Palembang. Based on the findings of artifacts since the early 20th century, the experts believe that Siguntang hill is a religious site, particularly for Buddhism. Nevertheless, evidence in the form of religious buildings (temple) has not been found. Therefore, the purpose of this study is to prove that this is a religious site which played an important role during the Sriwijaya era. The data were collected through excavation and literature study. Data analysis was performed with the identification of archaeological remains, then associated with form and function. The results of the study are statues, inscriptions, chinese ceramic fragmenst which describe Siguntang Hill is the site of religious or whorship center, a Buddhist pilgrim center and a community center of Sriwijaya. In later times, the Siguntang Hill has a role as a place of origin of Malay kings and place of oath. Keywords: siguntang hill, role, sriwijaya kingdom.
\end{abstract}

\begin{abstract}
Abstrak
Bukit Siguntang merupakan salah satu situs masa Kerajaan Sriwijaya di Palembang. Berdasarkan temuan artefak sejak awal abad ke-20, para ahli berkeyakinan bahwa Situs Bukit Siguntang adalah situs keagamaan, khususnya Buddha. Namun demikian, bukti-bukti adanya bangunan keagamaan (candi) sampai saat ini belum ditemukan. Tujuan dari penelitian ini adalah untuk mengetahui peranan Bukit Siguntang pada masa Kerajaan Sriwijaya berdasarkan bukti-bukti yang ditemukan. Data dikumpulkan melalui kegiatan ekskavasi dan kajian pustaka. Analisis data dilakukan dengan identifikasi tinggalan arkeologi, kemudian dikaitkan dengan bentuk dan fungsinya. Hasil penelitian adalah arca, prasast, pecahan keramik Cina yang menggambarkan, bahwa Bukit Siguntang merupakan situs keagamaan atau pusat peribadatan, pusat penziarah agama Buddha dan pusat pertemuan masyarakat pada masa Kerajaan Sriwijaya. Pada masa kemudian,Bukit Siguntang memiliki peran sebagai tempat asal-usul raja-raja di Dunia Melayu dan tempat melakukan sumpah.

Kata kunci: bukit siguntang, peranan, kerajaan sriwijaya.
\end{abstract}

\section{PENDAHULUAN}

Situs Bukit Siguntang adalah sebuah bukit kecil yang tingginya 26 meter di atas permukaan laut dan merupakan bentang lahan tertinggi di Kota Palembang. Bukit Siguntang oleh sebagian masyarakat Melayu di Sumatera dan Semenanjung Melayu dianggap suci, karena merupakan tempat asal leluhur orang- orang Melayu. Bukit Siguntang juga dianggap sebagai lokasi Parameswara, Raja Palembang yang menurunkan raja-raja di Semenanjung Melayu.

Penelitian pertama kali dilakukan oleh Westenenk pada awal abad ke-20 dan menemukan tiga fragmen arca, yang setelah disatukan merupakan bagian dari arca Buddha 
(Utomo 1985a, 151). Setelah itu penelitian secara berturut-turut dilakukan oleh $\mathrm{H}$. Luning pada tahun 1935 (Schnitger 1937, 1), Schnitger pada tahun 1935 dan 1936. Berdasarkan hasil penelitian di Bukit Siguntang pada tahun 1936, Schnitger (1937, 1-4) melaporkan adanya temuan berupa arca Buddha, pecahan prasasti, dan sisa-sisa bangunan dari bata, peta sebaran situs masa Sriwijaya (gambar 1). berkaitan tentang keletakan Sriwijaya. Ada yang berpendapat bahwa lokasi Sriwijaya ada di Palembang, Jambi, Riau, Kedah, dan Thailand.

Berdasarkan asumsi di atas, kemudian dilakukan serangkaian kegiatan penelitian di Palembang, yang awalnya dilakukan oleh Satyawati Suleiman dan tim pada tahun 1978 dan 1980. Tim ini menemukan pecahan keramik dari masa abad ke-10 (Suleiman 1984, 5).

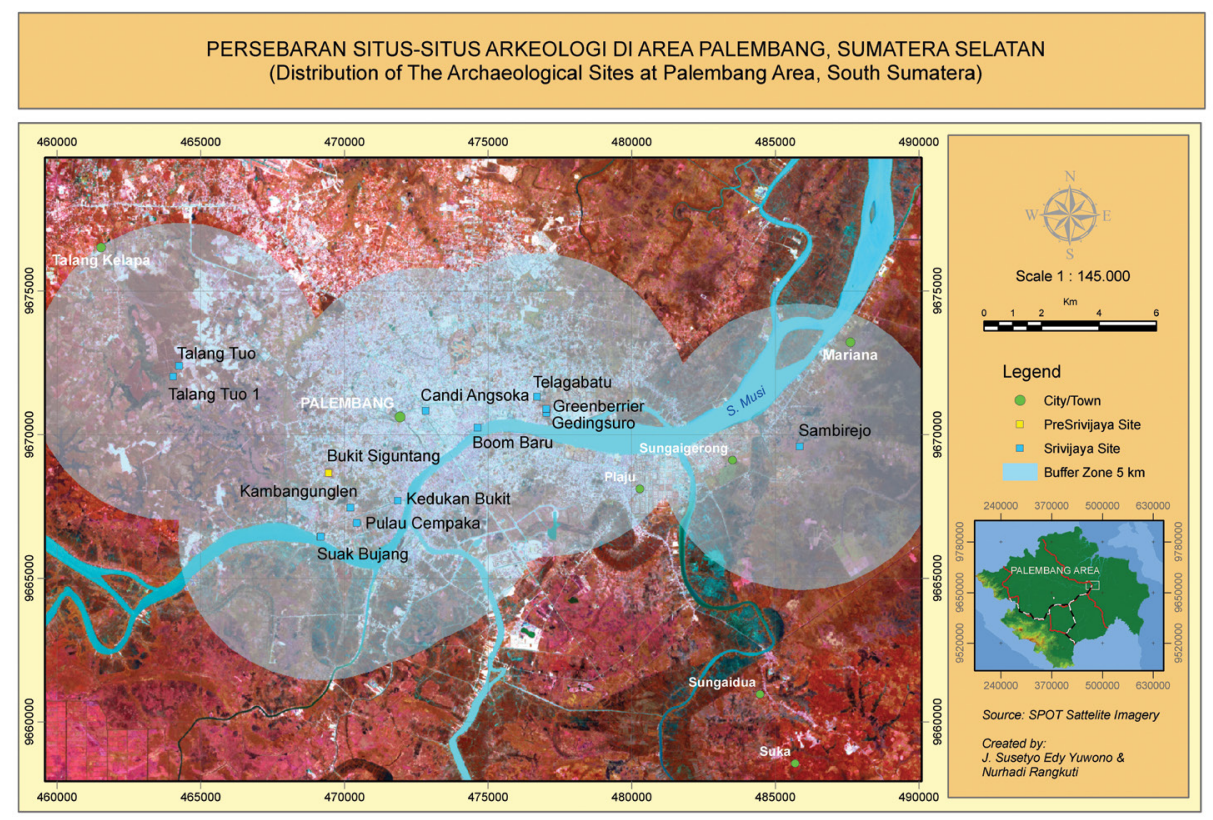

Gambar 1. Peta persebaran situs masa Sriwijaya di Palembang.

(Sumber: Dokumen Balar Sumatera Selatan)

Penelitian selanjutnya dilakukan oleh Dinas Purbakala pada tahun 1954, Lembaga Purbakala dan Peninggalan Nasional bekerjasama dengan The University of Pennsylvania Museum pada tahun 1975 (Bronson et al. 1976, 220-239). Hasil penelitian tersebut melaporkan bahwa dalam penelitian yang melibatkan tim dari Indonesia dan Amerika, tidak ditemukan pecahan keramik yang lebih tua dari masa Yuan (12801368). Berdasarkan temuan tersebut kemudian disimpulkan, bahwa Kerajaan Sriwijaya tidak berlokasi di Palembang (Bronson 1975, 9092; Adhyatman 1984, 3). Pernyataan tersebut kemudian menimbulkan polemik di antara para pakar, baik di bidang sejarah, arkeologi, epigrafi, maupun keramik. Polemik antar pakar
Di kaki Bukit Siguntang ditemukan pecahan keramik dari bahan batuan berglasir hijau kuning (olive green jar) atau dusun jar, karena banyak ditemukan di daerah orang Dayak Dusun di Kalimantan Utara. Keramik jenis ini berasal dari masa Dinasti Tang (618906). Hasil ini memberikan bukti, bahwa Situs Bukit Siguntang berasal dari masa Sriwijaya, yang oleh para ahli diyakini berkembang sejak abad ke-7-14 Masehi.

Untuk membuktikan keletakan Kerajaan Sriwijaya, maka Pusat Penelitian Arkeologi Nasional melakukan penelitian di Palembang dari tahun 1984-1992 dan Direktorat Perlindungan dan Pembinaan Peninggalan Sejarah dan Purbakala pada tahun 1985. Berdasarkan penelitian tersebut dapat 
ditemukan situs-situs dari masa Sriwijaya dan persebarannya di Palembang (Utomo, 1994, 1985a, 151-152; Tim Penelitian Arkeologi Palembang 1989, 10).

Penelitian geologi yang dilakukan oleh Yahdi Zaim di Situs Bukit Siguntang berhasil diketahui bahwa singkapan batuan yang terdapat di Bukit Siguntang terdiri dari lempung tufaan dengan lensa konglomerat yang merupakan ciri endapan sungai. Dengan demikian, Bukit Siguntang yang merupakan ujung dari satuan morfologi perbukitan, bagian timur, selatan, dan baratnya dikelilingi oleh rawa. Dataran rendah rawa-rawa ini merupakan daerah limbah banjir (flood plain) ( Zaim 1985a, 152). Endapan sedimen yang terdapat berupa endapan alluvial limbah banjir terdiri dari lempung yang sangat lunak dan lekat. Endapan alluvial sungai ini disebut low terrace yang berumur HolosenResen. Berdasarkan data ini dapat diketahui, bahwa di sekitar Bukit Siguntang dan Kota Palembang tidak didapatkan endapan sedimen laut, melainkan endapan sedimen alluvial limbah banjir dari Sungai Musi (Utomo 1985, 153).

Berdasarkan temuan data arkeologi dan geologi tersebut, maka dapat diperkirakan, bahwa lokasi Kerajaan Sriwijaya pada abad ke-7-11 Masehi berada di Palembang. Bukit Siguntang adalah salah satu situs masa Sriwijaya yang mempunyai peranan penting pada masa itu. Namun, peran apa sajakah yang pernah dimainkan oleh Bukit Siguntang di masa lalu? Bukti-bukti apa saja yang dapat digunakan untuk mendukung peranan tersebut? Dua pertanyaan inilah yang akan dijawab dalam tulisan ini. Dengan demikian, maka tujuan dari penelitian ini adalah untuk mengetahui buktibukti arkeologi yang dapat digunakan untuk mendukung peran Bukit Siguntang di masa Sriwijaya.

\section{METODE}

Bukit Siguntang terletak di Jalan Sultan Mansyur, Kelurahan Bukit Lama, Kecamatan Ilir Barat II, Palembang. Secara astronomis berada pada titik koordinat S 2059'34.3' E $104^{\circ} 45^{\prime} 08.1^{\prime}$ (gambar 2).

Untuk menjawab pertanyaan di atas, digunakan sumber data arkeologi yang dikumpulkan dari hasil pengamatan langsung berupa ekskavasi di Bukit Siguntang dan studi kepustakaan. Pengumpulan data dari ekskavasi dilakukan pada tahun 2013-2015 yang dilakukan oleh Balai Arkeologi Palembang. Data lainnya berasal dari laporan hasil penelitian terhadap

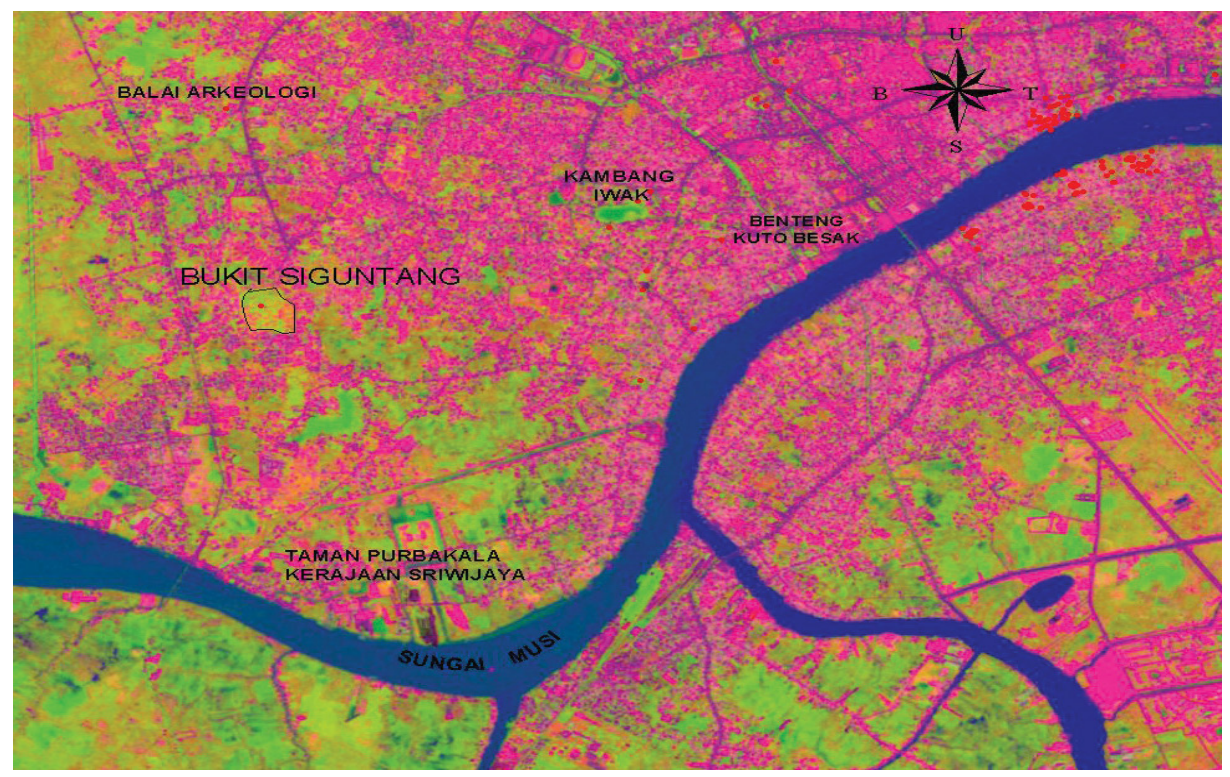

Gambar 2. Peta keletakan situs Bukit Siguntang di Palembang. (Sumber: Dokumen Balai Arkeologi Sumatera Selatan) 
situs-situs lain di Palembang yang telah dilakukan oleh berbagai pihak, baik yang telah dan belum diterbitkan.

Analisis data arkeologi dilakukan dengan metode deskriptif berdasarkan bentuk, kronologi, dan konteksnya. Setelah itu, kemudian, dilakukan proses sintesis atau interpretasi sesuai dengan tujuan penelitian. Sintesis data akan digunakan sumber sekunder yang membahas permasalahan terkait. Agar objektivitas kajian ini tetap terjaga, proses analogi atau komparasi data diterapkan untuk memperoleh akurasi jawaban dari sejumlah pertanyaan di atas. Adapun proses analogi atau komparasi diambil dari beberapa situs sejaman, baik yang ada di Palembang atau daerah lainnya yang ada kaitannya dengan Kerajaan Sriwijaya.

\section{HASIL DAN PEMBAHASAN}

\section{Bukti Sejarah dan Arkeologi di Bukit Siguntang}

Nama Bukit Siguntang sudah dikenal sejak lama, terbukti dengan penyebutannya dalam Kitab Sejarah Melayu yang ditulis pada tanggal 13 Mei 1612. Dalam kitab tersebut disebutkan:

"Adapun negeri Palembang itu, Palembang yang ada sekarang inilah. Maka di hulu Sungai Tatang ada sebuah sungai, Melayu namanya; di dalam sungai itu ada sebuah bukit bernama Bukit Si guntang; di hulu Gunung Maha Miru, di daratnya ada satu padang bernama Padang Penjaringan. Maka ada dua orang perempuan berladang, Wan Empo seorang namanya dan Wan Malini seorang namanya; dan keduanya berumah di Bukit Si Guntang itu, terlalu luas humanya, syahadan terlalu jadi padinya, tiada dapat terkatakan; telah hamper masak padi itu".

Kitab itu juga menceritakan turunnya makhluk setengah dewa ke Bukit Siguntang dan makhluk ini di kemudian hari menurunkan rajaraja puak Melayu di Sumatra dan Semenanjung Malaysia.

Di kalangan para arkeolog, Bukit Siguntang dikenal sebagai situs keagamaan, karena di tempat ini ditemukan pondasi bangunan kuno yang dibuat dari bata, arca Buddha berukuran besar dari batu granit, arcaarca buddhistis berukuran lebih kecil, pecahanpecahan tembikar, dan pecahan-pecahan keramik dari masa Dinasti Tang abad ke-7-10 Masehi (Utomo 1993, 5).

Arca Buddha dari batu granit ditemukan pada tahun 1920-an dalam keadaan tidak utuh dan terbagi menjadi beberapa bagian. Setelah direkonstruksi beberapa fragmen arca batu granit tersebut, ternyata berasal dari satu arca Buddha berukuran besar. Kepala arca ini awalnya sudah disimpan di Museum Nasional Jakarta, yang kemudian disatukan kembali dengan bagian badannya, sehingga dapat diketahui ukurannya, yakni $277 \mathrm{~cm}$. Sekarang arca ini terdapat di halaman Museum Sultan Mahmud Badaruddin, Palembang (Schnitger 1937, 3-4). Arca yang dipahatkan dalam posisi berdiri dengan mengenakan jubah yang berlipat-lipat ini, berdasarkan gaya seninya, diduga berasal dari abad ke-2-4 (Suleiman 1981, 4; 1984, 5). Namun, ada pendapat lain yang mengemukakan bahwa arca Buddha dari Bukit Siguntang ini berasal dari abad ke-6-7 Masehi (Suhaimi 1979, 36-37).

Arca digambarkan memakai jubah transparan yang menutupi kedua bahunya, berambut keriting dan bersanggul (usnisa) dan di dahinya terdapat bulatan (urna). Ciriciri ikonografi pada arca menunjukkan gaya Amarawati yang berkembang di India Selatan pada sekitar abad ke-2-5 Masehi. Namun, gaya ini masih tetap berkembang di Sri Lanka sampai abad ke-8 Masehi. Atas dasar ini, maka diperkirakan arca Buddha dari Bukit Siguntang ini berasal dari sekitar abad ke-7-8 Masehi (gambar 3).

Di bagian lembah Bukit Siguntang juga ditemukan fragmen arca Bodhisattwa, yaitu bagian kepala. Kepala arca ini digambarkan dengan rambut yang tersisir rapi dengan ikatan seutas pita yang berhiaskan kuntum bunga. Sebagaimana halnya arca Buddha dari batu granit, bagian badan arca ini ditemukan di 


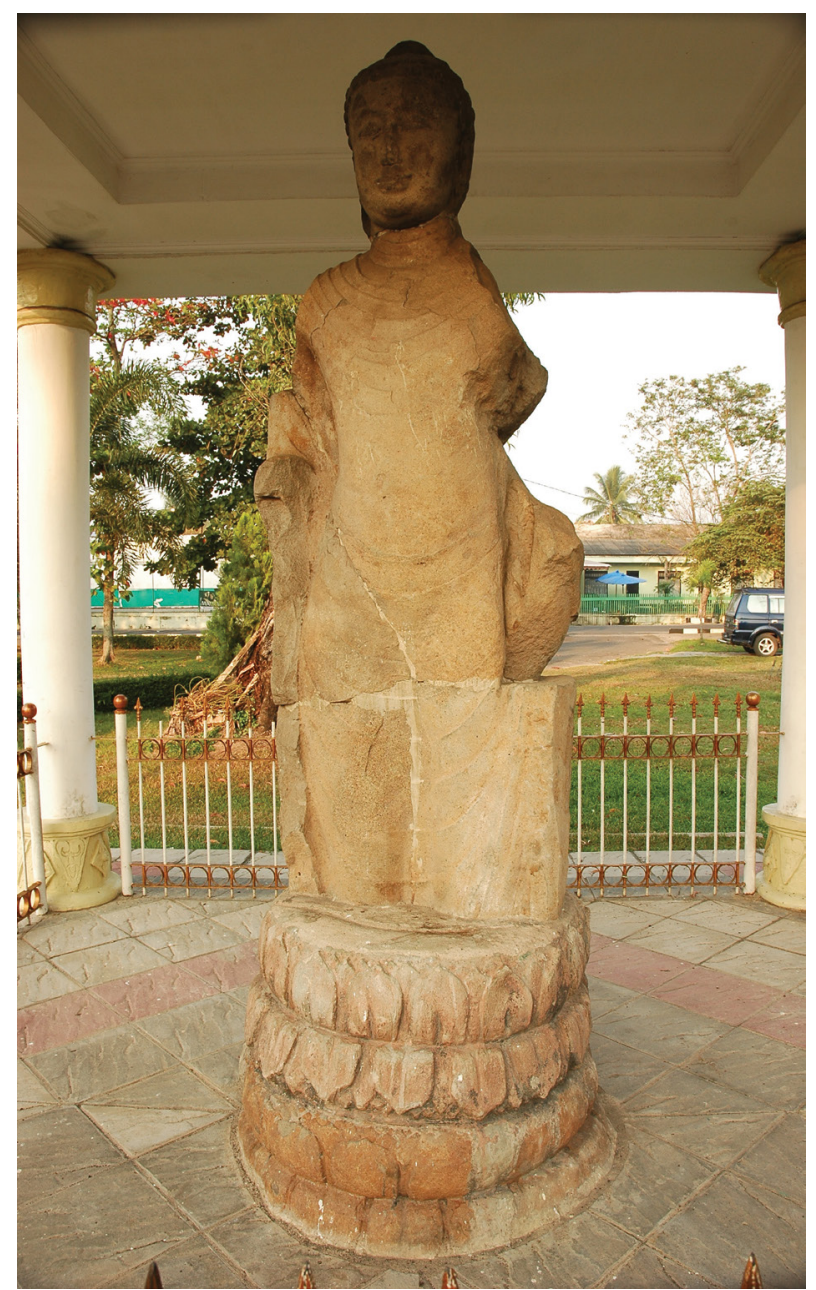

Gambar 3. Arca Buddha dari Situs Bukit Siguntang. (Sumber: Dokumen Balar Sumatera Selatan)

tempat yang berjauhan tetapi masih di daerah Bukit Siguntang. Bagian badannya digambarkan memakai kain dengan lipatan seperti wiru di bagian tengah. Kain yang dikenakannya itu diikat dengan sabuk dari kain yang lebar.

Selain di Bukit Siguntang oleh F.M. Schnitger (1937, 1-4) dilaporkan adanya temuan runtuhan stupa dari bahan batu pasir dan bata, fragmen prasasti dan arca Bodhisattwa berbahan batu, sebuah lempengan emas dengan tulisan yang berisikan ajaran Buddha, arca Lokeswara, dan arca perunggu Kuwera. Dari ekskavasi di situs ini ditemukan pecahan gerabah, keramik serta manik-manik. Sisa-sisa bangunan keagamaan yang tersisa di Bukit Siguntang hanya bagian kaki atau pondasinya saja, sedangkan sebagian besar pondasi bangunannya hilang sebagai akibat pembangunan pemukiman modern. Sisa-sisa berupa batu bata banyak berserakan di daerah kaki bukit. Menurut laporan arkeologis tahun 1954, pada waktu itu masih ditemukan bentuk denah sisa bangunan stupa. Selain itu, pernah ditemukan juga piring emas dan padmasana (Utomo 1985, 154). Sisa bangunan kuno dari batu bata tersebut diduga merupakan bagian dari vihara (Utomo 1993, 226).

Temuan yang menarik adalah fragmen prasasti yang ditulis dalam aksara Pallawa dan menggunakan bahasa Melayu Kuna, yang oleh J.G. de Casparis disebut dengan prasasti Bukit Siguntang. Prasasti Bukit Siguntang ini ditemukan pada tahun 1928 dalam keadaan tidak utuh lagi dan sekarang disimpan di Museum Taman Kerajaan Sriwijaya, Palembang. Prasasti ini terdiri dari 21 baris dan menyebut adanya peperangan, seperti tertera pada baris ke-10 yaitu: tida tahu pira marvyu(ha) atau tidak tahu berapa banyak yang berperang. Pada baris ke-5 terdapat kalimat: "vanak pramirahna" artinya banyak darah tertumpah. Kemudian baris ke-9: "pauravirakta" yang berarti merah (oleh darah) penduduknya, serta "mamañcak yam prajā" ini, yang diduga berkenaan dengan peperangan itu sendiri. Prasasti ini juga memuat kutukan kepada mereka yang berbuat salah (Casparis 1956, 2-6; Purwanti 1995, 98-103).

Pada awal tahun 1990-an di Bukit Siguntang ditemukan satu arca perunggu yang menggambarkan Buddha dalam sikap duduk, lengkap dengan prabha dan payung. Tampaknya arca ini menggambarkan tokoh Wairocana.

Hasil penelitian arkeologi oleh Pusat Penelitian Arkeologi Nasional tahun 1984 terdapat temuan berupa struktur bangunan bata, stupa batu, Arca Buddha, fragmen arca Boddhisatwa, kepala Buddha dari bahan perunggu, arca Lokeswara, arca Kuwera dari bahan perunggu, pedestal berbentuk bulat, pedestal berbentuk bantalan teratai, piring emas, pecahan keramik, dan pecahan tembikar. Kecuali struktur bangunan bata, 
pecahan keramik dan tembikar, seluruh temuan arkeologis tersebut sudah dibawa ke Museum Pusat Jakarta, dan Museum Sultan Mahmud Badaruddin Palembang (Tim Pemetaan dan Penelitian Geologi dan Arkeologi 1984, 19).

Pada penelitian tanggal 9-14 September 2013 oleh Balai Arkeologi Palembang ditemukan struktur bata di sisi bagian timur Bukit Siguntang (Purwanti 2013, 12-14). Berdasarkan sisa-sisa susunan batanya, diduga berasal dari dua susunan bangunan yang berbeda. Hal ini terlihat dari perbedaan ukuran dan warna bata yang digunakan untuk menyusun bangunan. Susunan bata pertama berbentuk segiempat dengan ukuran $380 \mathrm{~cm}$ x $385 \mathrm{~cm}$, tebal $74 \mathrm{~cm}$ dan tinggi $20 \mathrm{~cm}$, terdiri dari lima lapis bata (gambar 4). Pada bagian dalam keempat sudut struktur bangunan membentuk lengkungan, sehingga bagian dalamnya membentuk oval. Di dalam struktur bangunan ini terdapat struktur bangunan lain berdenah segi empat dengan ukuran $200 \mathrm{~cm} \times 225 \mathrm{~cm}$, tinggi $20 \mathrm{~cm}$ dan tebal $21 \mathrm{~cm}$.

Susunan batu bata kedua terdiri dari 5 lapis bata, membujur arah Barat-Timur sepanjang $300 \mathrm{~cm}$, tinggi, $29 \mathrm{~cm}$, dan lebar 73 $\mathrm{cm}$. Susunan bata ketiga terdiri dari dua lapis bata terletak di sebelah selatan susunan bata ketiga berjarak sekitar $43 \mathrm{~cm}$. Tebal atau tinggi susunan bata ini adalah $12 \mathrm{~cm}$.

Berdasarkan ukuran bata penyusun dapat diketahui adanya tiga jenis bata yang berbeda pada susunan bata pertama sampai ketiga, yakni bata berukuran panjang $27 \mathrm{~cm}$, lebar 15 $\mathrm{cm}$, dan tebal $6 \mathrm{~cm}$. Bata jenis kedua berukuran panjang $37 \mathrm{~cm}$, lebar $15 \mathrm{~cm}$, dan tebal $5 \mathrm{~cm}$. Sedangkan bata lainnya berukuran panjang 18 $\mathrm{cm}$, lebar $18 \mathrm{~cm}$, dan tebal $5 \mathrm{~cm}$. Sedangkan pada susunan bata keempat disusun dari dua jenis bata berbeda, yaitu bata berwarna putih dengan ukuran panjang $21 \mathrm{~cm}$, lebar $6 \mathrm{~cm}$, dan tebal $6 \mathrm{~cm}$. Sedangkan ukuran bata berwarna

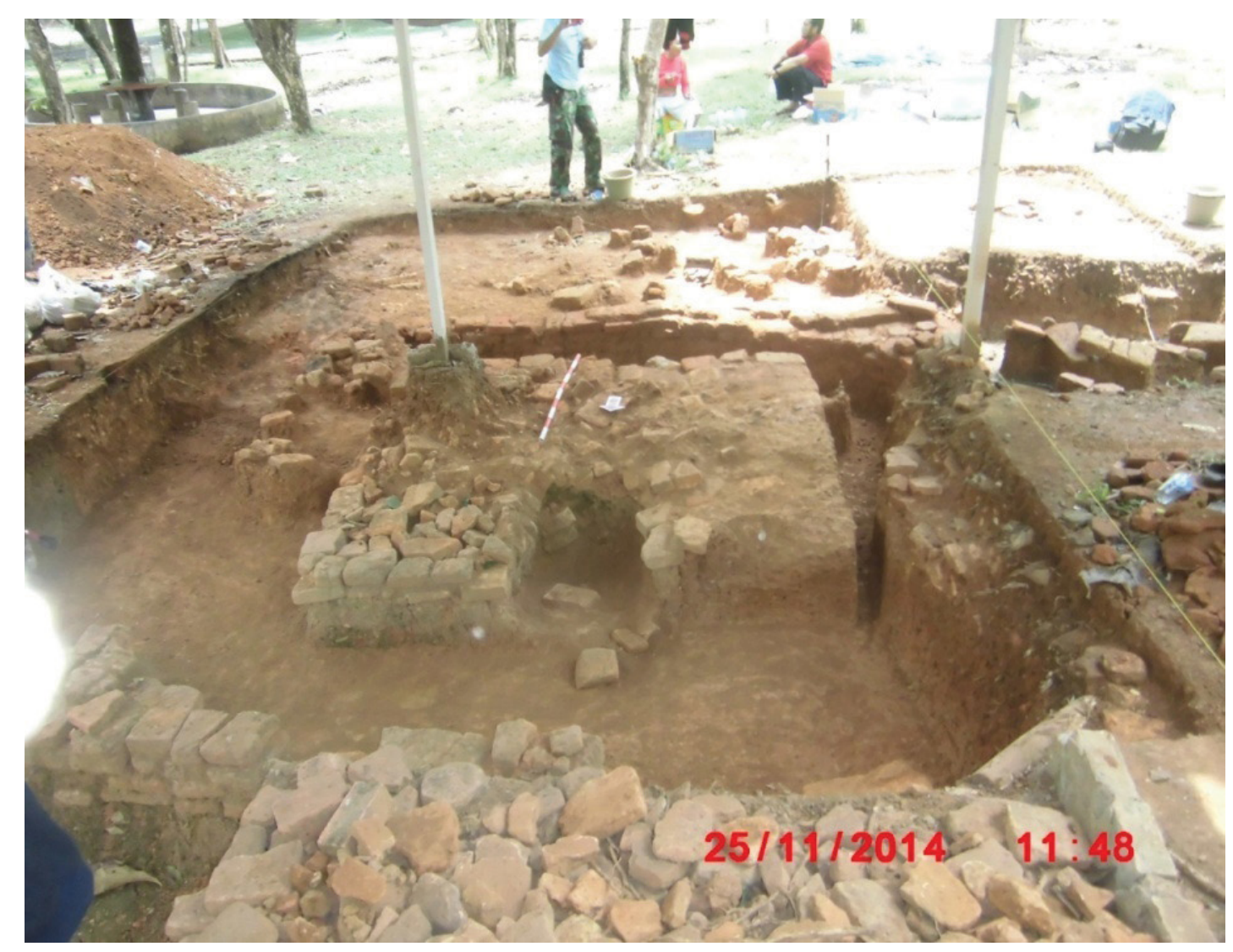

Gambar 4. Struktur bata berdenah segi empat.

(Sumber: Dokumen Balai Arkeologi Palembang) 
merah adalah panjang $20 \mathrm{~cm}$, lebar $16 \mathrm{~cm}$, dan tebal $4 \mathrm{~cm}$.

Di daerah kaki sebelah baratdaya Bukit Siguntang, di satu tempat yang bernama Tanjung Rawa, dilaporkan ada temuan struktur bata ketika penduduk sedang menggali tanah untuk bangunanmasjid. Berdasarkan pengamatan pada bata yang lepas dari konteksnya, dapat diketahui bahwa bata tersebut telah dibentuk miring dan melingkar pada salah satu sisinya. Bata lepas ini mungkin berasal dari suatu bangunan yang berbentuk lingkaran, mungkin bangunan stūpa. Pecahan keramik yang ditemukan pada permukaan tanah sebagian besar merupakan keramik tipe Yueh dari pertengahan pertama abad ke-10 Masehi (Adhyatman 1984, 25). Di samping itu, ditemukan juga sebuah mangkuk kecil yang berglasir warna hijau keabuan dan tidak dapat tembus cahaya (McKinnon 1979, 41-47). Warna glasir seperti itu adalah khusus untuk wadah tipe Yueh yang mempunyai pertanggalan abad ke-9-10 Masehi.

Selain struktur bangunan di bagian lereng selatan Bukit Siguntang ini, ditemukan juga struktur bata di puncak bukit dengan ukuran bata-bata penyusunnya lebih besar, dibandingkan yang ada di lereng, yaitu $41 \mathrm{~cm}$ x 21 x $9 \mathrm{~cm}$. Struktur ini hanya terdiri dari satu lapis bata dengan panjang $81 \mathrm{~cm}$, lebar $41 \mathrm{~cm}$ dan tebal $9 \mathrm{~cm}$ (gambar 5). Di bawah struktur

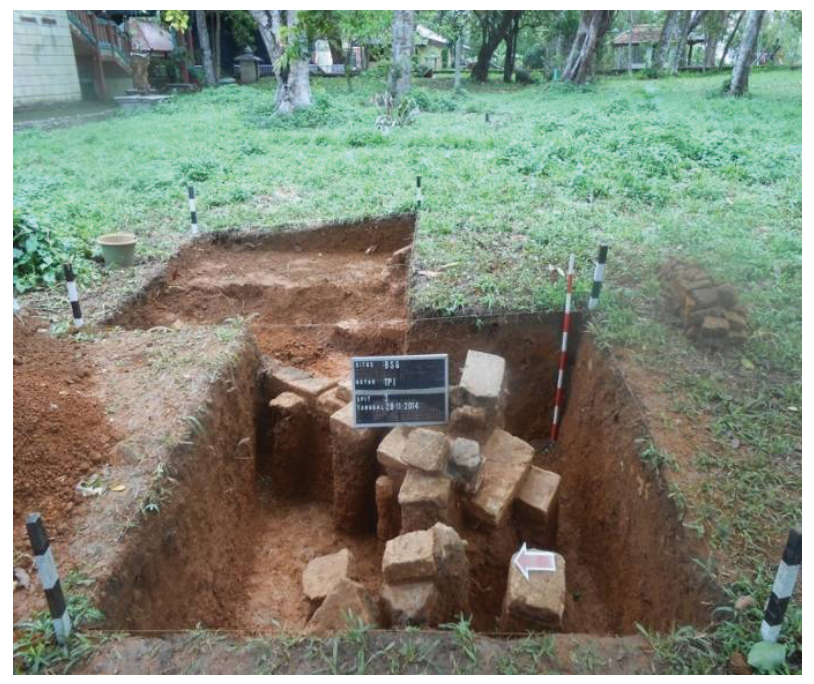

Gambar 5. Struktur bata di puncak Bukit Siguntang. (Sumber: Dokumen Balai Arkeologi Palembang) bata ini ditemukan periuk dalam keadaan pecah dan rapuh. Lokasi struktur bata ini berada di belakang makam Putri Kembang Dadar.

Temuan bata-bata yang diduga merupakan sisa-sisa bangunan juga terdapat di depan makam Panglima Bagus Kuning dan makam Panglima Bagus Karang pada tahun 1992 (SPSP Jambi 1992, 7-12). Ada tiga bentuk bata kuno yaitu bata berdenah empat persegi panjang, lingkaran, dan segitiga. Salah satu bata berbentuk empat persegi panjang berukuran panjang $51,5 \mathrm{~cm}$, lebar $15 \mathrm{~cm}$, dan tebal $12 \mathrm{~cm}$. Bata berbentuk lingkaran memiliki garis tengah $20 \mathrm{~cm}$ dan tebal $7,5 \mathrm{~cm}$, sedangkan bata berbentuk segitiga berukuran $11 \mathrm{~cm}$ pada masing-masing sisi. Di antara bata-bata yang ditemukan di sini ditemukan juga dua bata dengan cap kaki binatang dan gores tulisan.

Selain sisa-sisa bangunan dari bata, ditemukan juga artefak yang berada di dalam cungkup makam Panglima Bagus Kuning dan Panglima Bagus Karang. Artefak pertama terletak di atas Makam Panglima Bagus Kuning berupa bantalan arca (asana) yaitu tempat untuk mendirikan sebuah patung (padma) yang berukuran panjang $68 \mathrm{~cm}$, lebar $34 \mathrm{~cm}$ dan tinggi $27 \mathrm{~cm}$ (gambar 6). Sisi bagian luarnya melingkar, dan sisi dalamnya cenderung rata. Kemungkinan merupakan satu sisi (1/4 bagian) bawah padma untuk mendirikan arca. Berdasarkan informasi yang berhasil dihimpun dari juru kunci makam, dahulunya batu ini merupakan bagian atau menjadi salah satu nisan

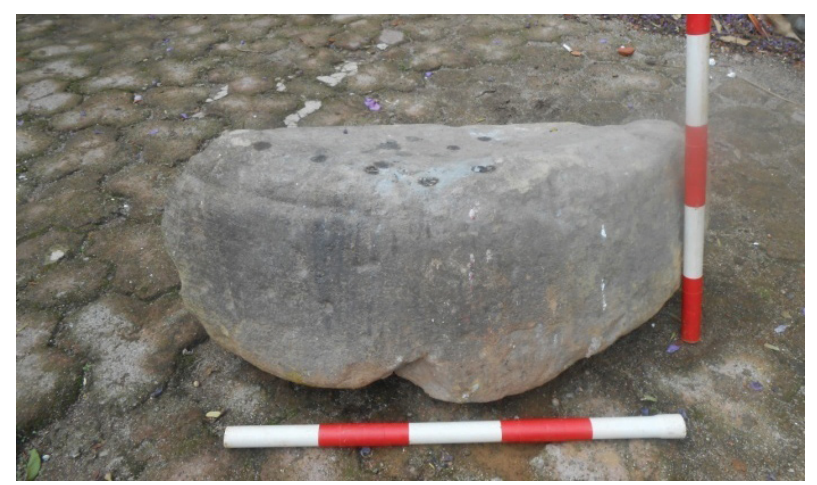

Gambar 6. Fragmen bantalan arca.

(Sumber: Dokumen Balai Arkeologi Palembang) 
dari Panglima Bagus Kuning. Saat dilakukan pemerian batu ini diletakkan di atas makam tersebut, tetapi, tidak menjadi nisan.

Artefak kedua merupakan pecahan dari sebuah batu. Di sisi kanan dan kiri batu tersebut patah. Dari jenis batuan, kemungkinan sama dengan batu yang digunakan untuk menulis prasasti dan arca (batu andesit). Ukuran batu tersebut lebar $28 \mathrm{~cm}$, panjang $25 \mathrm{~cm}$ dan tinggi $23 \mathrm{~cm}$. Menurut penuturan penjaga makam, batu ini dahulunya merupakan salah satu bagian nisan Panglima Bagus Karang. Ada kemungkinan bahwa bangunan ini merupakan sisa-sisa bangunan candi, tempat bernaung arca Buddha yang sekarang berada di halaman museum Sultan Mahmud Badaruddin II.

Dengan ditemukannya struktur bata yang diduga berasal dari dua bangunan yang berbeda di lereng dan satu struktur bata di puncak Bukit Siguntang, serta bata-bata kuno membuktikan hasil penelitian yang pernah dilakukan oleh Schnitger pada tahun 1936, dan hasil survei yang dilakukan pada tahun 1954, yang menginformasikan adanya temuan sisa-sisa bangunan stupa (Schnitger 1937, 3-4; Soekmono, dkk. 1985, 42-43 ). Dugaan adanya bangunan stupa yang diduga merupakan bagian dari bangunan keagamaan ini diperkuat dengan temuan arca Buddha, Jambala, Wairocana, dan sebagainya di Bukit Siguntang (Schnitger 1937, 3-4). Arca Buddha yang tingginya hampir 4 meter sengaja ditempatkan di bagian puncak.

\section{Peran Bukit Siguntang Pada Masa Kerajaan Sriwijaya}

Dengan adanya sejumlah temuan tersebut, dapat diduga bahwa kekuasaan Kerajaan Sriwijaya berlangsung dari abad ke-7 sampai abad ke-14 Masehi. Bukit Siguntang, yang terkait dengan keberadaan Kerajaan Sriwijaya ini merupakan situs keagamaan, khususnya agama Buddha (Manguin 2014, 239). Lokasi ini juga dijadikan sebagai tempat ziarah bagi para pemeluk agama Buddha di masa lalu. Peran sebagai tempat ziarah ini tampaknya terus berlanjut sampai sekarang, terbukti dengan masih adanya sebagian masyarakat yang mendatangi makam-makam yang ada di puncak Bukit Siguntang.

Selain sebagai tempat peribadatan dan peziarahan, peran penting Bukit Siguntang juga tercatat dalam "Kitab Sejarah Melayu" yaitu sebagai tempat asal-usul raja-raja Melayu di Nusantara, baik yang ada di Indonesia, Sumatera khususnya, maupun raja-raja yang pernah berkuasa di Singapura, Malaysia, Brunei Darussalam dan Patani, Thailand Selatan. Bahkan, pada masa Sultan Mahmud Badaruddin bin Sultan Bahauddin, Bukit Siguntang pernah dijadikan sebagai tempat untuk mengambil sumpah bagi penduduknya yang sedang bertikai, agar berdamai. Adapun lokasi dilakukannya persumpahan tersebut adalah di makam raja Segentar Alam (Sevenhoven 1971, 23). Bahkan, Wolters (1986, 4) bahwa Bukit Siguntang merupakan jantung Kerajaan Sriwijaya.

Dengan mengacu pada banyaknya situssitus masa Sriwijaya di daerah Palembang Barat dan temuan prasasti Siddhayatra, Soeroso (2014, 3-4) dalam laporan penelitiannya menyebutkan, bahwa Bukit Siguntang dan sekitarnya merupakan titik pertemuaan berbagai komunitas pada masa itu, serta tempat mengungkapkan rasa kegembiraan atas kemenangan perjalanan suci Raja Sriwijaya dan pengikutnya. Lebih lanjut dikemukakan bahwa luapan kegembiraan tersebut tidak dilakukan pada kawasan puncak Bukit Siguntang, melainkan di lereng-lerengnya, khususnya di sekitar Kedukan Bukit tempat dibangunnya wanua yang terletak di sebelah selatan Bukit Siguntang.

Peran penting Bukit Siguntang ini juga diperkuat dengan pemberitaan I-tsing yang menyebutkan, bahwa Sriwijaya sebagai pusat Agama Buddha. I-tsing juga menyebutkan, bahwa di Sriwijaya tinggal lebih dari 1000 bhiksu dan menyarankan agar para pendeta yang ingin belajar ke India sebaiknya datang dulu 
ke Sriwijaya untuk belajar di sana (Takakusu 1896, 3).

\section{KESIMPULAN}

Bukit Siguntang merupakan bukit tertinggi yang ada di Palembang, sehingga pemilihan lokasi ini sebagai tempat peribadatan tentunya sudah melalui pertimbangan yang matang. Keletakan Bukit Siguntang di daerah yang paling tinggi tentunya juga merupakan refleksi kosmologis dalam agama Buddha.

Bukit Siguntang mengandung tinggalan arkeologi berupa arca, struktur bata, prasasti, pecahan keramik Cina yang berasal dari masa Kerajaan Sriwijaya, yaitu abad ke-7-10 Masehi. Selain data arkeologi, bukti keberaddan Bukit Siguntang juga disebut dalam sumber sejarah yaitu Kitab Sejarah Melayu dari abad ke-17 Masehi.

Pada masa Sriwijaya, Bukit Siguntang berperan penting sebagai tempat peribadatan dan peziarahan bagi pemeluk agama Buddha. Peran lain yang dimainkan oleh Bukit Siguntang adalah sebagai lokasi pertemuan komunitas yang ada di Sriwijaya. Dengan adanya ketiga peran penting inilah, maka Bukit Siguntang dianggap sebagai jantung Kerajaan Sriwijaya.

Pada masa Islam Bukit Siguntang dianggap tempat asal-usul raja-raja Melayu di Nusantara. Peran lain Bukit Siguntang pada masa Islam adalah sebagai tempat orang melakukan persumpahan jika terjadi perselisihan antar warga.

\section{DAFTAR PUSTAKA}

Adhyatman, Sumarah. 1984. "Kunjungan ke Bukit Siguntang Palembang, Sumatera Selatan." Amerta 8: 25-33.

Bronson, Bennet. 1973. Laporan Penelitian Arkeologi di Sumatera. Jakarta: Lembaga Purbakala dan Peninggalan Nasional.

Bronson, Bennet dan Jan Wisseman. 1975. "An Archaeological survey in Sumatera." Sumatera Research Bulletin 4 (1): 87-94. 1978. "Palembang as Sriwijaya: the lateness of early cities in southern Southeast Asia." Asian Perspectives 19 (2): 220-239. The University Press of Hawaii.
Casparis, J.G.de. 1956. Selected Inscriptions from the $7^{\text {th }}$ to the $9^{\text {th }}$ Century, A.D. (Prasasti Indonesia II). Bandung: Masa Baru

Manguin, Piere-Yves. 2014. "Palembang dan Sriwijaya Hipotesis Lama, Penelitian Baru (Palembang Barat), dalam Kadatuan Sriwijaya. Edisi Revisi. Depok: Komunitas Bambu-EFEO-Pusat Arkeologi Nasional. (197-280).

McKinnon, E.E. 1979. "Spur-marked Yueh-tye sherds at Bukit Siguntang", dalam JMBRAS $52(2): 41-47$.

Purwanti, Retno. 1995. "Perang Pada Masa Sriwijaya: Tinjauan terhadap PrasastiPrasasti Abad VII Masehi." Jurnal Penelitian Balai Arkeologi Bandung Nomor: 2/ November/1995: 98-103.

2013. "Temuan Struktur Bata Di Situs Bukit Siguntang." Laporan Pendokumentasian. Balai Arkeologi Palembang (Tidak terbit).

Schnitger, F.M. 1937. The Archaeology of Hindoo Sumatra. Leiden: E.J. Brill.

Sevenhoven, J. L. van. 1971. Lukisan Tentang Ibukota Palembang. Jakarta: Bhratara.

Soekmono, R. Dkk.,1985. "Beberapa Hasil Perjalanan.” Amerta 3 (37-50). Jakarta: Pusat Penelitian Arkeologi Nasional.

Soeroso. 2014. "Laporan Singkat Penelitian Arkeologi Palembang." Kerjasama Balai arkeologi Palembang dan Badan Penelitian, Pengembangan dan Inovasi Daerah Provinsi Sumatera Selatan (tidak terbit).

Suaka Peninggalan Sejarah dan Purbakala Jambi. 1992. "Laporan Studi Teknis Situs Bukit Siguntang." Suaka Peninggalan Sejarah dan Purbakala Wilayah Jambi, Sumatera Selatan dan Bengkulu (Tidak terbit).

Suhaimi, Nik Hasan. 1979. "The Bukit Siguntang Buddha." Dalam JMBRAS III (2): 38-39.

Suleiman, Satyawati. 1984. "Laporan Dari Indonesia." Amerta 7 (3-13). Jakarta: Pusat Penelitian Arkeologi Nasional.

1981. Sculpture of Ancient Sumatra. Jakarta: Pusat Penelitian Arkeologi Nasional.

Takakusu, J. 1896. A Record of Buddhist Religion as Practise in India and the Malay Archipelago (A.D. 671-695) by I-Tsing. Oxford: Hart. 
Tim Penelitian Arkeologi Palembang.t.t. "Agama Buddha di Sriwijaya." Dalam Himpunan Penelitian Arkeologi Palembang Tahun 19841992, 221-230. Jakarta: Pusat Penelitian Arkeologi Nasional (Belum terbit). 1989. "Laporan Penelitian Arkeologi Palembang Tahap V/1989." Jakarta: Pusat Penelitian Arkeologi Nasional. (Belum terbit).

1992. "Himpunan Penelitian Arkeologi Palembang Tahun 1984-1992.“ Jakarta: Pusat Penelitian Arkeologi Nasional. (Belum terbit).

Utomo, Bambang Budi. 1985a. "Penelitian Arkeologi di Daerah Lembah Sungai Musi, Palembang." Dalam Rapat Evaluasi Hasil Penelitian Arkeologi II, 151-162.
Utomo, Bambang Budi 1985. "Karanganyar as a Srivijayan site: New Evidence for the study of settlement pattern of the Srivijayan period." Dalam SPAFA Final Report Consultative workshop on Archaeological and Environmental Studies on Srivijaya, 273289. Bangkok: SPAFA Co-ordinating unit.

1993. "Sriwijaya Di Palembang Sebagai Pusat Agama Buddha." Dalam Sriwijaya dalam Perspektif Arkeologi dan Sejarah. B7-1-B7-10. Pemerintah Daerah Tingkat I Propinsi Sumatera Selatan, 1993.

Wolters, O.W. 1986. "Restudying some Chinese writings on Srivijaya." Indonesia 42: 1-41. 